that De Saussure is the author of the term; but I have long been foiled by its omission from the index of the famous "Voyages dans les Alpes." In "Open Air Studies," however, I ventured to compare the mammillations of a glaciated surface to those upon an antique wig; but all the time, it seems, Mr. Whymper held the key of the matter for us, in a passage which has escaped the memory even of Prof. Bonney (see "IceWork," I 896, p. Io). Mr. Whymper, in fact ("Scrambles amongst the Alps," fourth edition, I893, p. I33), supplies the reference to De Saussure ; and in the "Voyages dans les Alpes," I 804, tome ii, p. 435, par. I06I, we may read of what are styled in the margin " montagnes moutonnées." De Saussure states that behind Envionne (the modern Envionnaz), in the upper valley of the Rhône, "ces rondeurs contiguës et répetées forment en grand l'effet d'une toison bien fournie, ou de ces perruques que l'on nomme aussi moutonnées." In face of this, there is no longer any need to tax the credulity of our pupils with a fanciful explanation, which we seem to have forced even upon French-speaking peoples.

Royal College of Science for Ireland, Grenvilie A. J. Cole. Dublin, February I 7 .

\section{The Age of the Present Canadian Flora.}

Prof. D. P. Penhallow has recently identified some fragments of wood found in the Leda clays of Montreal, as Picea nigra, the common black spruce. This is another addition to the group of plants which represent our present knowledge of the flora of Canada in Pleistocene times. This Pleistocene flora may now be taken to include not merely the plants found in these Leda clays and in the clays believed to be equivalent to them in age in Ontario, but also the ancestors of the present inland maritime flora found on the shores of the Great Lakes, hundreds of miles from the sea-coast, and of the plants which are common to Europe and America, and which include so many arctic and sub-arctic, as well as northern temperate species. The inland maritime plants, and probably also the sub-arctic species now found so far south as the headlands of Lake Superior, made their way to their present localities during the deposit of the Leda clays when a considerable part of Eastern Canada was submerged. Six of the species which occur in the Leda clays at Ottawa and Montreal, and thirteen of the inland maritime plants, as well as several of the Lake Superior subarctic species, are also European, showing that at that period the intermingling of the American and European floras was well established, but leaving open the possibility of these plants common to the two continents being even older than the period of the Leda clays.

The intermingling of the Asiatic and American floras appears to have taken place at a still earlier period. The oldest known representatives of the existing Canadian flora are those few identical species found by Mr. Lester $\mathbf{F}$. Ward in the Laramie rocks of the Western United States-rocks which Sir William Dawson refers to the Lower Eocene. Two of those identified now occur in both Japan and Canada ; and one, still living in Japan, has, if correctly identified, become extinct on the American continent. Again, among the Leda clay and inland maritime plants there are several species which are likewise common to the two countries. The intermingling of Asiatic and American plants evidently took place prior to the upheaval of the Rocky Mountain chain, as the extensive flora peculiar to British Columbia, Oregon, and southward, is almost without a repre. sentative in Japan. This British Columbia flora, so well represented by various species of Claytonia, Lupinus, Trifolium, Astragalus, Saxifraga, \&c., as well as Conifere, is of more recent birth-probably Later Tertiary and Post-Tertiary.

The most recent creations in Canada would appear to be the plants which-well represented by Compositx, an order of no great antiquity-are now so marked a feature of the prairics of Manitoba and the surrounding country-prairies which in some places are still in process of formation.

\section{A. T. DRummond.}

\section{Children's Drawings.}

WiTH regard to young children drawing upside down, I have for some time past collected observations. It is certainly true, that a great many children do draw in this way; on the other hand, many from the first draw the right way up. I have seen a boy of four, when asked to draw a rook on a haystack, begin at the bottom of the paper with the rook's back, and gradually work his way up to the haystack; he then turned it round, and handed it to me to look at, evidently realising that it was inverted.

I do not think the explanation depends in any way on the inversion of the retinal image. If a child, who draws upside down when drawing on a horizontal table, is asked to draw on a blackboard placed vertically, he will draw everything the right way upwards. It seems to me, that the explanation simply is that the child has to draw an object, which he has seen in a vertical plane, on paper placed in a horizontal plane-an extremely difficult task to him-and it is a mere question of convenience to him at which end he begins, both being equally wrong from his point of view. This will also explain why children sometimes look at picture-books upside down, and also why small children are much more ready to draw objects, which they have been accustomed to see in a horizontal plane, such as a plate with oranges on it, than an erect object.

The Old Palace, Richmond.

Rina ScotT.

\section{THE RÖNTGEN RAYS.}

THE discovery by Prof. Röntgen of the rays which bear his name has aroused an interest perhaps unparalleled in the history of physical science. Reports of experiments on these rays come daily from laboratories in almost every part of the civilised world. A large part of these relate to the methods of producing Röntgen photographs, and the application of the "new photography" to medical and other purposes. A considerable amount of work has, however, been done on the physical properties of these rays; this has entirely confirmed the results stated by Röntgen in the paper in which he announced his discovery. The freedom of refraction of these waves, in which they are different from ordinary light, has been the subject of direct experiments made by $M$. Perrin and by Dr. Joly, while Dr. Lodge and others have confirmed the absence of any deflection in the magnetic field which differentiates these rays from the ordinary kathode rays.

Up to the present, however, no phenomena have been observed which enable us to say whether these waves are or are not transverse vibrations of very small wavelength, longitudinal vibrations, or even vibrations at all. Nothing of the nature of polarisation or of interference has been described. The absence of polarisation can at the present stage of the investigation hardly be pressed as an argument against these rays being transverse vibrations. For, of the three methods of producing polarisation in light - reflection, refraction, and absorption-only the latter is available for these rays. Now the number of substances which produce sensible polarisation in ordinary light by absorption is very small, and unless a much larger number possess this property for the Röntgen rays, it is hardly likely that, even if there are such substances, they would have been discovered in the three months which have elapsed since the publication of Röntgen's discovery. I may remark that I have made a large number of experiments on the opacity to these rays of plates of tourmaline (I) with their axes crossed, (2) with their axes parallel, testing the intensity of the rays which came through in some cases by their action on a photographic plate, in others by the discharge they produced in an electrified plate on which they were incident. The result of these experiments was entirely negative, for although the tourmaline plates produced very considerable absorption of the rays, no difference was detected between the absorption when the axes were crossed and when they were parallel. It is very desirable that a large number of substances should be tested in this way.

M. C. Henri has made the very interesting observation that an opaque coin coated with the phosphorescent sulphide of zinc will allow these rays to pass through it ; the details of this experiment will be received with much

$$
\text { NO. I } 374 \text {, VOL. 53] }
$$


interest. I have found that when the Röntgen rays pass through any substance, they make it for the time being a conductor of electricity, even although the substance is in its normal state a perfect insulator. Thus solid paraffin, paraffin oil, solid sulphur, ebonite, mica, air--all conduct electricity when the Röntgen rays pass through them. This explains the fact observed by Righi, Bergman, and myself, that an electrified plate in air loses its charge when exposed to these rays, whether it be electrified positively or negatively. The air is converted into a conductor by these rays, and the charge escapes through it. It is not necessary that a gas should surround the plate, as I have found that the leakage takes place whatever the medium surrounding the plate may be. That this leakage is due to the condition of the insulator, rather than to that of the plate, is shown by the fact that it occurs when the plane of the electrified discs is parallel to the rays, as well as when it is at right angles to them. The air through which these rays have passed retains traces of conductivity for some little time after the rays have ceased to pass through it ; this can be shown by blowing the air, from a place where the rays are plentiful, against a charged disc placed where there are only a few rays; the rate of leak from this disc is much increased by the blast.

With the assistance of Mr. J. A. McClelland, of 'Trinity College, Cambridge, I have made a large number of measurements of the rate of leak from positively and negatively electrified discs surrounded by air, and have found that the rate of leak in the two cases is almost identical. We have also made a series of measurements of the rate of leak through air at different pressures; the rate of leak is greater at a high pressure than at a low one, and is over a wide range of pressures approximately proportional to the square root of the pressure. The rate of leak is also greater in air than in hydrogen, being at atmospheric pressure about twice as great in air as it is in hydrogen, while the leakage through carbonic acid gas is faster than that through air.

The leakage of electricity through non-conductors is, I think, due to a kind of electrolysis, the molecule of the non-conductor being split up, or nearly split up, by the Röntgen rays, which act the part played by the solvent in ordinary electrolytic solutions. If the air through which the rays are passing is ionised, the number of ions would, according to the well-known law of dissociation, be proportional to the square root of the pressure, provided the amount of ionisation is small. Thus the result we obtained for the rate of leak through air at different pressures, indicates that the rate of leak is proportional to the number of ions.

The view that the air is turned by these rays into an electrolyte, is supported by some experiments made in the Cavendish Laboratory, by Mr. Erskine Murray, on the contact difference of potential between metal plates in air. He finds that when the Röntgen rays are passing through the air in the neighbourhood of the plates, the plates (as far as their potential differences are concerned) behave as if they were connected by an electrolyte.

Mr. C. J. R. Wilson has investigated, in the Cavendish Laboratory, the effects produced by Rontgen rays on the condensation of clouds caused by the expansion of air, and has found that when the rays pass through the vessel in which the cloud is formed, the cloud is very much denser than when the rays are absent, showing that these rays increase the number of nuclei which act as centres of cloud condensation. The ions with their electrical charges would act as such nuclei, so that this, again, is in favour of the view that these rays turn the air into an electrolyte. These experiments seem to show that these rays exert a powerful disintegrating effect on the molecules of substances through which they pass, and suggest that their use may throw light on some questions of molecular structure. It would be interesting, for example, to find the rate of leak through gases which are reputed to be monatomic, such as mercury vapour, argon, and helium. Again, if air and other gases can be made to act as electrolytes, we could use a mercury dropping arrangement, similar to that employed by Ostwald to measure the potential difference between metals and liquid electrolytes, to measure, by means of it, the potential difference between metals and various gases through which the Röntgen rays are passing.

By measuring the rate of leak from a disc charged to a fixed potential, we can compare the efficiency, as producers of Röntgen rays, of different tubes or of the same tube at different periods. The conclusion I have arrived at, by means of such measurements, is that bulbs generally improve for some time after they are sealed off from the pump, and attain a maximum efficiency, after which they begin to deteriorate.

Some measurements of the absorption of Röntgen rays by various thicknesses of metal, have led me to the conclusion that the Röntgen rays are not all of the same kind. The experiments were made by measuring the change of the rate of leak from an electrified disc, produced by changing the number of sheets of tinfoil interposed between the disc and the phosphorescent tube. When a small number of sheets of tinfoil were interposed, the addition of another sheet of tinfoil produced a very considerable diminution in the rate of leak; when, however, the phosphorescent bulb was a very good one, a considerable leakage remained when the number of sheets of tinfoil was considerable, and this "residual leakage" diminished but slowly as the number of sheets of tinfoil was increased. This seems to indicate that while there are some rays which are rapidly absorbed by the tinfoil, there are others which can pass through it with comparative facility. It is only when using one or two of the most efficient bulbs that I have remarked this "residual leakage," but with these bulbs when in their most efficient state it was very marked.

\section{J. J. THOMSON}

\section{THE DEEPEST SOUNDING YET KNOWN.}

I N Nature (vol. lii. p. 550, October 3, I895), I mentioned that H.M.S. Penguin, Commander A. F Balfour, R.N., had found in the Pacific Ocean deeper water than any yet known in lat $23^{\circ} 40 \mathrm{~S}$., long. $175^{\circ}$. $0 \mathrm{~W}$., but had failed to reach the bottom owing to breakage of the wire at 4900 fathoms.

Captain Balfour has been enabled to try again, and I have just received the announcement of his obtaining three satisfactory soundings of over 5000 fathoms.

The deepest trustworthy sounding heretofore known is 4655 fathoms near Japan, obtained by U.S. S. Tuscarorce in 1874 .

'The deepest of the Penguin's casts is 5155 fathoms, or 500 fathoms (3000 feet) deeper; but it is especially remarkable that the three casts now obtained are not in the same hollow, but are separated by areas of considerably less water, the two extreme soundings being $45^{\circ}$ miles apart.

The usual abysmal red clay was brought up by the sounding-tube on two occasions; on the third the wire broke.

Mr. V. Thorpe, surgeon of the Penguin, reports that a microscopic examination of the specimen from 5147 fms. shows that the remains of siliceous organisms are almost, if not entirely, absent. The mineral particles are in a minute state of disintegration, and consist of exceedingly fine flocculent matter, mixed with pumice and other glossy volcanic products, green crystals of augite and reddish crystals of pelagonite.

These deep hollows furnish fresh evidence to the observed fact that all the extreme depths in the ocean

NO. I 374 , vOL. 53] 